ISSN: 0213-2087 eISSN: 2444-7080

DOI: https://doi.org/10.14201/shhc2021391747

\title{
EL EJÉRCITO ESPAÑOL EN VÍSPERAS DE ANNUAL
}

\section{The Spanish Army on the Eve of Annual}

\author{
Fernando PUELL DE LA VILLA \\ Instituto Universitario General Gutiérrez Mellado (UNED) \\ https://orcid.org/0000-0001-8107-560X
}

Recibido: 02/02/2021 Revisado: 23/04/2021 Aceptado: 30/04/2021

RESUMEN: El artículo intentará responder a la siguiente pregunta: ¿hasta qué punto incidió la estructura orgánica, la doctrina táctica, la capacitación operativa y la dotación armamentística del ejército español, tanto las del peninsular como las del desplegado en Marruecos, sobre el desastre de Annual? A tal objeto, se analizarán dichos factores en el contexto de la segunda década del siglo xx, pudiendo llegarse a la conclusión de que efectivamente fueron determinantes en la errónea planificación y desarrollo de la operación dirigida al sometimiento del Rif oriental y para que se produjese el precipitado abandono de aquella posición y el consiguiente desplome de la Comandancia General de Melilla.

Palabras clave: Siglo xx; Organización militar; Oficialidad; Reclutamiento; Táctica; Armamento.

ABSTRACT: The article will try to answer the following question: to what extent did the organization structure, tactical doctrine, operational training and weapons endowment of the Spanish Army, both the peninsular one and the deployed in Morocco, affected the Annual disaster? To this end, these factors will be analyzed in the context of the second decade of the twentieth century, and it can be concluded that they were indeed decisive in the erroneous planning and development of the operation aimed at subjugating the eastern Rif and for the hasty abandonment of that position and the consequent collapse of the General Command of Melilla.

Key words: Twentieth century; Military organization; Officiality; Recruitment; Tactics; Armament. 


\section{INTRODUCCIÓN}

España libró una cruenta y larguísima guerra para controlar la zona norte del Protectorado de Marruecos, la mayoría de cuya población no reconocía la autoridad del sultán ni tampoco la del jalifa que debía gobernarla en su nombre, y mucho menos la española. La total inexperiencia de las autoridades españolas en administrar un protectorado, a diferencia de Francia que gobernaba en ese régimen la vecina Túnez y la lejana Indochina, propició que, inicialmente, ningún gobierno acertase a definir con suficiente precisión y claridad la política a seguir ni la estrategia a aplicar, lo que condicionó el no siempre airoso papel desempeñado por las unidades que combatieron en aquel agreste territorio. Pero también influyó en ello la situación del ejército metropolitano, tanto respecto a su organización, a sus reglamentos tácticos, a sus cuadros de mando, a sus clases de tropa y a los recursos materiales disponibles.

Lo publicado recientemente sobre las campañas de Marruecos, desde la óptica castrense, es bastante escueto: una sucinta obra de carácter colectivo y divulgativo, sustentada básicamente en el exhaustivo y minucioso, aunque bastante acrítico, trabajo elaborado por una ponencia de oficiales del Servicio Histórico Militar ${ }^{1}$. Y sobre la acción de Annual, que tanta atención concitó en su día y sobre la que han aparecido algunas monografías en los últimos años -unas noveladas y otras hagiográficas o reivindicativas ${ }^{2}$-, tal vez lo más interesante e innovador sea un ensayo poco difundido y conocido ${ }^{3}$. Y la casi total ausencia de obras sobre el ejército en tiempos de Alfonso XIII ha sido afortunadamente mitigada por la publicación de una excelente tesis doctoral, leída en el Departamento de War Studies del King's College London en $2001^{4}$.

Con estos mimbres, junto con las fuentes utilizadas por el autor de este artículo en algunos de sus trabajos, se intentará responder a la siguiente pregunta: ¿hasta qué punto incidió la estructura orgánica, la doctrina táctica, la capacitación operativa y la dotación armamentística del ejército español, tanto las del peninsular como las del desplegado en Marruecos, sobre el desastre de Annual?

A ese objeto, el artículo se compartimentará en cuatro apartados. En el primero, se analizará la estructura, organización y doctrina del Ejército de Tierra,

1. Carrasco, Antonio (coord.): Las Campañas de Marruecos (1909-1927). Madrid: Almena, 2001, e Historia de las campañas de Marruecos. Madrid: Servicio Histórico Militar, 1947-1981, 4 v.

2. A título de muestra de las unas y de las otras, vid. AlBi DE la Cuesta, Julio: En torno a Annual. Madrid: Ministerio de Defensa, 2014; Bellido ANDREu, Antonio: El "Alcántara" en la retirada de Annual: la laureada debida. Madrid: Ministerio de Defensa, 2006; CAzORLA PRIETO, Luis María: Las semillas de Annual: novela. Córdoba: Almuzara, 2015; Francisco, Luis Miguel: Morir en África: la epopeya de los soldados españoles en el Desastre de Annual. Barcelona: Crítica, 2014, y PANDo Despierto, Juan: Historia secreta de Annual. Madrid: Temas de Hoy, 1999.

3. Caballero Echevarría, Fernando: Annual, los factores que llevaron al desastre: análisis del intervencionismo español en Marruecos entre 1898 y 1928. Tarifa: ImagenTa, 2016.

4. Herrero Pérez, José Vicente: The Spanish Military and Warfare from 1899 to the Civil War. London: Palgrave Macmillan, 2017. 
prestando también atención, de una parte, a la indefinición de la política a seguir en Marruecos, debido tanto al desconocimiento de la forma de administrar un protectorado como a la brevedad de las legislaturas y a la transitoriedad de los gobiernos, y de otra, a los planes y proyectos para la modernización del ejército elaborados antes y después de la Gran Guerra. En el segundo apartado, se expondrán las características de los cuadros de mando, su formación académica y su capacidad operativa, así como la incidencia de la crisis de las Juntas de Defensa sobre la oficialidad peninsular y colonial. En el tercero, se analizarán los principales rasgos de la tropa de la época: origen social, forma de reclutamiento y nivel de adiestramiento. $\mathrm{Y}$ en el cuarto, los procedimientos tácticos que se emplearon en aquellas campañas y el equipamiento de las unidades intervinientes en los años previos al desastre de Annual.

\section{ORganización DEL EJÉRCITO}

En 1912, cuando se creó el Protectorado de Marruecos, el ejército español se distinguía poco del predominante en Europa continental, que, en líneas generales, se mantenía fiel al modelo establecido tras la derrota de Francia en 1870. Solo se había avanzado en la universalización del servicio militar y en la organización de las reservas, aunque las restricciones presupuestarias impedían realizar prácticas de movilización, así como en la adquisición de algunas ametralladoras.

Las unidades de infantería eran el núcleo del ejército; su armamento básico era el fusil Mauser de $7 \mathrm{~mm}$, adquirido durante la Guerra de Cuba, y seguía pendiente que los artilleros renunciaran a calificar la ametralladora como pieza de artillería. Las de caballería no disponían de vehículos y continuaban utilizando sables y lanzas. Artillería contaba con cañones de distintos usos y calibres, e incluso de algunos vehículos de motor para remolcarlos. El Cuerpo de Ingenieros sí había realizado notables progresos; el telégrafo era de uso corriente, el teléfono de campaña aseguraba el enlace entre las unidades combatientes y comenzaba a utilizarse la radio, conocida todavía como "telegrafía sin hilos»; también gestionaba una unidad de dirigibles y unos cuantos aeroplanos.

Debido sin duda a la situación descrita, los ministros de la Guerra se afanaron por reformar el ejército y los cuadros de mando a hacer propuestas en el mismo sentido. Nunca antes ni después de este período los militares escribirían tanto. De los cientos de títulos editados, de los miles de artículos aparecidos en los dos o tres periódicos militares que se publicaban a diario y en la docena de revistas profesionales mensuales, una notable proporción trataba de reformas ${ }^{5}$. Sus autores

5. Por poner un par de ejemplos, vid. Gallego Ramos, Eduardo: Proyecto de reorganización y mejora del Ejército de Tierra. Guadalajara: Imp. del Colegio de Huérfanos de la Guerra, 1905; EQUIS, El Capitán: El problema militar en España: apuntes para un estudio sincero y al alcance de todos. Burgos: Imp. J. Saiz y Comp. ${ }^{a}$, 1916, y BeTA, Comandante (seud, de José García Benítez): Apuntes para historiar tres años de reformas militares. Madrid: Imp. de Bernardo Rodríguez, 1917. 
comentaban, alababan o criticaban los proyectos ministeriales y también exponían sus propios planes o lo que se hacía en el extranjero. La guerra de Marruecos avivó estos debates, la incidencia de la Gran Guerra los atemperó y, a su término, volvieron a resurgir con más fuerza ${ }^{6}$.

Líderes y grupos políticos sumaron su voz a esta algarabía general. Manifiestos y programas incluían siempre un apartado para definir su modelo de ejército y los cambios que harían cuando llegaran al poder. En general, los partidos con posibilidades de gobernar prometían potenciar la fuerza armada y aumentar su presupuesto. Los extraparlamentarios, mucho más radicales, planteaban desde su sustitución por una milicia popular hasta la supresión del servicio militar ${ }^{7}$.

No obstante, las estrecheces financieras normalmente impedían que estos planes y propuestas llegasen a buen puerto o que, en otros casos, salieran del parlamento muy mutilados. La realidad era que los gastos de personal consumían gran parte del presupuesto militar y la necesidad de pagar el sueldo al desmesurado número de oficiales existente mermaba las partidas dedicadas a adiestrar a las tropas, comprar armamento, adquirir campos de tiro y de maniobras, habilitar cuarteles y mejorar infraestructuras.

\subsection{Mando y Estado Mayor}

Aquel estado de cosas obedecía a un conjunto de factores; entre ellos, los cuatro más relevantes eran: 1) la imprecisión sobre quién ejercía el mando efectivo sobre el ejército, 2) la despreocupación de los gobiernos de la Restauración por los temas castrenses, 3) la delegación de su gestión en el ministro de la Guerra y su entorno militar, y 4) la carencia de un organismo planificador que diera continuidad y estabilidad a la política militar.

Sobre lo primero, la Constitución de 1876 había atribuido al monarca «el mando supremo del ejército y armada " ${ }^{\circ}$. Tal cláusula no tenía antecedente alguno, salvo los muy imprecisos que aparecían en las de 1812 y 1869, ambas redactadas en circunstancias muy excepcionales, y daba pie a que el rey pudiera inmiscuirse en la gobernanza de los ejércitos, como en efecto hizo Alfonso XIII en varias ocasiones. La Ley Constitutiva del Ejército de 1878 intentó aclarar el tema, que había sido bastante controvertido, y se precisó que el ejercicio del "mando supremo" estaba sometido al preceptivo refrendo gubernamental, salvo en el caso de que se ejerciera en tiempo de guerra9 9 . Como tal salvedad parecía vulnerar la Constitución, al hacer recaer sobre el monarca la responsabilidad de una derrota, Sagasta solventó

6. Schulze SchneIder, Ingrid: La prensa político-militar en el reinado de Alfonso XIII. Madrid: Centro de Estudios Políticos y Constitucionales, 2003.

7. ARtola, Miguel: Partidos y programas políticos 1808-1936. Madrid: Aguilar, 1975, t. II.

8. Constitución de la Monarquía Española, 29 de junio de 1876, art. 52.

9. Ley Constitutiva del Ejército, 29 de noviembre de 1878, arts. 4 y 5: Gaceta de Madrid (en notas sucesivas GM), 30 de noviembre de 1878 . 
en parte el problema en 1889, estableciendo que, en caso de que se pusiera al frente del ejército, sus órdenes serían refrendadas por el general en jefe de la fuerza ${ }^{10}$.

Tal estado de cosas, que tendría gravísimas consecuencias, era sintomático de las especialísimas relaciones establecidas entre la Corona y los ejércitos. Sin embargo, mucho más importante fue el vínculo que se fue creando entre ambas instituciones. Los militares llegaron a considerarse como un estamento autónomo, dotado de estructuras de poder paralelas a las de la Administración del Estado y dependientes en línea directa del monarca. Y como además se toleró que los militares intervinieran activamente en política, se propició la presencia de generales en las Cortes y que estos arrastraran a una cohorte de jefes y oficiales de la guarnición madrileña, ávidos de promocionar y situarse. Los que no hallaban acomodo en un partido buscaron arrimo a la sombra de la Casa Real, cuyo Cuarto Militar creció en plantilla e influencia durante el reinado de Alfonso XIII. Militares políticos y militares palatinos constituyeron la base de lo que se llamó «Ejército de Madrid», que controlaba de hecho el Ministerio de la Guerra ${ }^{11}$.

El que los ministros del ramo fuesen siempre generales hasta noviembre de 1917, cuando el nombramiento de Juan de la Cierva rompió con una práctica que se remontaba al siglo xviII, no debe considerarse demasiado determinante. El principal obstáculo para establecer una política militar estable y bien definida obedecía a la transitoriedad de los gobiernos, al frecuente relevo del titular de la cartera de Guerra y a la falta de un órgano que la planificase a largo plazo.

Entre 1909 y 1921, es decir, en los doce años transcurridos entre las debacles del barranco del Lobo y de Annual, se produjeron veinte relevos en la Presidencia del Consejo de Ministros y rondó los siete meses el mandato de los ocho políticos que desempeñaron el cargo: los conservadores Allendesalazar, Dato, Maura y Sánchez de Toca, y los liberales Canalejas, García Prieto, Moret y Romanones. Y los relevos en el Ministerio de la Guerra fueron todavía más frecuentes, siendo por tanto menor el tiempo de permanencia en el cargo, a excepción del general Luque, que lo desempeñó durante cuatro años y medio, primero con Canalejas (1910-1912) y después dos veces con Romanones (1913 y 1915-1917), y del general Echagüe, a quien Dato confió el puesto durante su primer gobierno (1914-1915). Esto explica la abundancia de proyectos de reforma de mayor o menor calado y el que tan a menudo acabasen en nada al cesar en el cargo sus promotores ${ }^{12}$.

Los empleos medios e inferiores de la oficialidad renegaban de aquel desbarajuste, que achacaban a un generalato muy politizado y más interesado en medrar que en atender a las necesidades del ejército. Su descontento contribuye a explicar la aparición de las llamadas Juntas de Defensa, una organización pseudosindical que desestabilizó el régimen de la Restauración entre 1917 y 1922, es decir,

10. Ley Adicional a la Constitutiva del Ejército, 19 de julio de 1889, art. 2: GM, 20 de julio de 1889

11. Seco Serrano, Carlos: "Relaciones entre la Corona y los Ejércitos", Revista de Estudios Políticos, 55,1987 , pp. 27-54

12. Herrero: Op. cit., 2017, pp. 7-12. 
precisamente en el contexto de Annual, tema que se abordará con más detenimiento al tratar de los cuadros de mando.

También existía un generalizado consenso sobre la necesidad de crear un organismo que diese continuidad a la política militar y que esta no estuviese supeditada a los frecuentes cambios de gobierno. El primer paso en este sentido lo había dado en 1904 el general Linares, ministro de la Guerra de Antonio Maura, al segregar las cuestiones administrativas de las operativas y encomendar estas al Estado Mayor Central (EMC), un órgano de carácter exclusivamente técnico para dar estabilidad y continuidad a los planes de defensa y encargarse de garantizar la operatividad de unidades ${ }^{13}$.

Al no haberse delimitado con suficiente claridad los ámbitos competenciales del ministro y del EMC, enseguida se produjeron tensiones, llegando incluso a cuestionarse su constitucionalidad ante la posibilidad de que su jefe pudiera arrogarse la función de comandante en jefe del Ejército, función atribuida al rey. También la clase política terció en el asunto; una parte de ella se opuso a la creación del EMC por creer que restaba libertad de acción al gobierno y otra, lo utilizó para cortocircuitar determinadas propuestas de reforma, argumentando que era el instrumento apropiado para plantearlas ${ }^{14}$.

A causa de aquellas controversias, en 1913, Luque, con la excusa de recortar la burocracia ministerial, lo suprimió y encomendó sus funciones a un nuevo departamento de rango bastante modesto: la Sección de Estado Mayor y Campaña ${ }^{15}$. $\mathrm{Al}$ año siguiente, nada más iniciarse la Gran Guerra, Echagüe intentó restaurarlo, definiéndolo como «centro donde radique la resolución de todas las cuestiones puramente técnicas, en nada referidas al mando, gobierno y administración de las tropas», al objeto de corregir las causas que condujeron a su supresión, y creó otro organismo -el Consejo Superior del Ejército- para unificar criterios entre el ministro y el jefe del EMC ${ }^{16}$. La caída del gobierno de Dato dio al traste con estos planes y finalmente fue Luque quien lo restableció en 1916, concebido esta vez como órgano eminentemente consultivo y encargado de la preparación y dirección de la guerra, siendo la mayor innovación que su jefe, en caso de guerra, se constituiría en comandante general del Ejército, pasando el EMC a ser su Estado Mayor de Operaciones ${ }^{17}$.

13. Puell de la villa, Fernando: «El Ejército de Tierra en tiempos de la Gran Guerra: reorganizaciones y reformas", Revista de Historia Militar, extraordinario 1, 2019, p. 27.

14. BETA: Op. cit., 1917, pp. 21-25.

15. "Los proyectos militares del último gobierno", La Correspondencia Militar, 29 de octubre de 1913.

16. Discurso del Ministro de la Guerra, Sr. Conde del Serrallo: Diario de Sesiones del Congreso de los Diputados, 18 de diciembre de 1914.

17. Real Decreto de 23 de enero de 1916: GM, 25 de enero de 1916. 


\subsection{Intentos de reforma}

Tras la dimisión de Maura a consecuencia de los graves sucesos en Barcelona y Melilla de 1909, Luque, nombrado ministro de la Guerra por Canalejas, se dedicó por entero a sacar adelante la Ley de Reclutamiento y Reemplazo de la que más adelante se hablará y, resuelto este tema, presentó a las Cortes tres Proyectos de Ley con los que pretendía resolver los problemas de personal: exceso de generales, ingreso y formación de las clases de tropa y reglamento de recompensas. El primero y el tercero fueron desestimados y solo el segundo, dirigido a dignificar la figura del sargento, fue aprobado ${ }^{18}$.

El 12 de noviembre de 1912, Canalejas fue asesinado por un anarquista en la Puerta del Sol y Romanones se impuso como sucesor suyo en contra de García Prieto, lo que provocó la quiebra del Partido Liberal ${ }^{19}$. El nuevo gobierno, con las Cortes cerradas, difundió una declaración programática a finales de enero de 1913, anunciando su intención de reorganizar el ejército en profundidad.

A ese efecto, al reanudarse las sesiones parlamentarias en octubre, Luque envió al Congreso un Proyecto de Ley Orgánica Militar, que establecía un contingente de 445.000 hombres, encuadrados en dos Ejércitos, denominados Peninsular y Colonial. El primero se estructuraba en tres líneas: la Primera articulada en ocho divisiones -una por Región Militar- con un total de 215.000 efectivos; la Segunda, compuesta por el mismo número de divisiones, agruparía 90.000, y la Tercera, concebida como Ejército Territorial, dotada con 60.000. Y el segundo, encargado de guarnecer Ceuta y Melilla y de operar en el recién creado Protectorado de Marruecos, encuadraría 80.000 efectivos, incluyendo indígenas y voluntarios. Como Romanones dimitió a los dos días, el proyecto fue retirado ${ }^{20}$.

A los nueve meses de constituirse el gobierno de Dato se rompieron las hostilidades en Europa, debido a lo cual se consideró necesario garantizar que, en caso de que España se viera obligada a entrar en guerra, existiese la infraestructura defensiva imprescindible para hacer frente a la situación. Como primera medida, Dato reestructuró por decreto la Junta de Defensa Nacional, organismo creado por Maura en 1907 para coordinar la actuación del Ejército y de la Armada, integrado por el presidente del Consejo de Ministros y los ministros, subsecretarios y jefes de Estado Mayor de ambos ramos, y el general Echagüe, al que le había confiado la cartera de Guerra, creó un Gabinete Militar en su ministerio para intentar paliar la

18. Ley disponiendo que en lo sucesivo haya dos categorías en las clases de tropa de las Armas y Cuerpos combatientes; una constituida por el Soldado, Soldado de primera y los Cabos, y otra por los Sargentos, Brigadas y Suboficiales, 15 de julio de 1912: GM, 18 de julio de 1912.

19. Martorell Linares, Miguel Ángel: «La crisis parlamentaria de 1913-1917: la quiebra del sistema de relaciones parlamentarias de la Restauración”, Revista de Estudios Políticos, 96, 1997, pp. 137-161.

20. "Los proyectos militares del último gobierno", La Correspondencia Militar, 29 de octubre de 1913. 
desaparición del EMC ${ }^{21}$. El plan elaborado por este gabinete consistía en, aparte de restaurar el EMC, reestructurar la reserva, aumentar el contingente y el material de artillería, configurar un Servicio de Aviación, y habilitar campos de tiro ${ }^{22}$. La oposición de los liberales a la reforma fue de tal calibre que provocó la caída del gobierno y, con ella, todos aquellos proyectos.

El 9 de diciembre de 1915, el mismo día en que Romanones volvía a hacerse cargo del gobierno, declaró que daría cima a las reformas militares pendientes y Luque anunció que presentaría un amplio plan de reformas. Pero antes, decretó que todos los generales, jefes y oficiales deberían superar determinados ejercicios físicos y teóricos para cumplir las condiciones de aptitud para el ascenso; la implementación de esta disposición fue la espoleta que desencadenaría la crisis de las Juntas de Defensa ${ }^{23}$. En agosto de 1916, Luque dio publicidad a sus proyectos en un pequeño folleto, que fue muy aplaudido por la prensa, pero irritó a la oposición; en parte debido a ello, terminaron tan mal como los de Echagüe. La reforma consistía básicamente en una reorganización territorial, la reestructuración del Ejército Operativo y la consabida reducción de plantillas. Respecto a lo primero, pretendía equilibrar los contingentes movilizables, atendiendo a razones demográficas, sin modificar las sedes y demarcaciones de las regiones militares, pero poniendo bajo la dependencia de los gobernadores militares provinciales un nuevo organismo, denominado Zona de Reclutamiento y Movilización, capaz de movilizar rápidamente a los reservistas y de requisar el material automóvil. El Ejército de Operaciones se organizaba de la misma forma que en 1913 y en el Protectorado de Marruecos se creaba, en vía de ensayo, una Legión Extranjera ${ }^{24}$.

Como se ha visto, ninguno de los grandes proyectos de Luque y de Echagüe tuvo buen final, en parte debido a la corta duración de las legislaturas. Pero la indefinición y titubeos sobre los objetivos de política de defensa y la falta de interés por abordar seriamente la reforma militar llevaron a la mayoría de los oficiales a adoptar posturas victimistas y a la inacción. Sin embargo, una minoría magnificó los problemas existentes -realmente graves en materia de personal-y decidió organizarse en Juntas de Defensa.

La prepotencia de sus promotores y la debilidad del ya muy desgastado sistema político de la Restauración se llevaron por delante los gobiernos de García Prieto y de Dato durante el verano de 1917 y en noviembre, al formar de nuevo gobierno García Prieto, los dirigentes de las Juntas exigieron que la cartera de Guerra fuera ocupada por un político civil y el generalato impuso el nombramiento de Juan de la Cierva. Este abordó por Real Decreto una pretendidamente ambiciosa

21. Reales Decretos de 30 de marzo de 1907 y de 28 de abril de 1915: GM, 31 de marzo de 1907 y 29 de abril de 1915, respectivamente.

22. Discurso del Ministro de la Guerra, Sr. Conde del Serrallo: Diario de Sesiones del Congreso de los Diputados, 18 de diciembre de 1914.

23. Real Decreto de 4 de enero de 1916: GM, 6 de enero de 1916.

24. LuQue y COCA, Agustín de: Antecedentes para un Proyecto de Ley Orgánica Militar que en su dia ha de presentarse a las Cortes. Madrid: Depósito de la Guerra, 1916. 
reforma estructural, que el general Marina, ministro de la Guerra del Gobierno de Concentración Nacional, que formó Maura en marzo de 1918, dio rango de Ley, sin variar su contenido 25 .

La que impropiamente ha pasado a la historia con el nombre de Ley de La Cierva concibió el ejército como «escuela permanente de mando, instrucción y preparación para la guerra» y su principal objetivo fue estabilizar las plantillas, reducir la exagerada cifra de cuadros de mando y aumentar substanciosamente las retribuciones, mediante la introducción de los quinquenios, primer antecedente de los actuales trienios de antigüedad en el servicio.

Para ello consolidó la división territorial de la Península en ocho regiones militares y asignó dos divisiones orgánicas a cada una de ellas, integradas por otras tantas brigadas. Con la pretensión de amortizar el excedente de personal, concedió el pase voluntario a la situación de reserva a los coroneles, con el sueldo completo y la categoría de generales honoríficos, y a los tenientes coroneles, con categoría y sueldo de coronel. Para el resto de los empleos, estableció topes de edad, al cumplir los cuales todo oficial pasaba a la denominada Escala de Reserva Retribuida, si conservaba determinadas condiciones de aptitud, o a la situación de retirado, en caso contrario. Por último, reguló las categorías de las clases de tropa -cabo, sargento y suboficial-, a los que se ofreció la posibilidad de alcanzar el grado de capitán de la citada escala, previa superación de un cursillo en una academia especial. Es decir, en plena Guerra Mundial, las únicas reformas que llegaron a buen término fueron las dirigidas a regular temas de personal, yendo a engrosar el archivo del parlamento los planes de modernización estructural.

\subsection{Estructura orgánica}

Durante el reinado de Alfonso XIII, la organización castrense trató parsimoniosamente de reajustarse a la situación creada por las campañas en Marruecos. El territorio peninsular estaba compartimentado en ocho regiones militares, con cabeceras en Madrid, Sevilla, Valencia, Barcelona, Zaragoza, Burgos, Valladolid y La Coruña. Al frente de cada una de ellas estaba un teniente general, que recibía el título de capitán general. De él dependían las unidades que guarnecían la demarcación y era el responsable del alistamiento de nuevos reclutas y de la movilización de los reservistas, efectivos con los que, teóricamente, debía organizarse un cuerpo de ejército en tiempo de guerra. Las islas Baleares y las Canarias constituían sendas capitanías generales, que desempeñaban cometidos similares a los de las regiones peninsulares en materia de reclutamiento y movilización. Las plazas de Ceuta y Melilla eran dos mandos territoriales independientes denominados, según la época, comandancias generales o gobiernos militares y, en 1913, se creó una

25. Real Decreto de 7 de marzo de 1918 y Ley de Bases para la Reorganización del Ejército, 29 de junio de 1918: GM, 8 de marzo de 1918 y 30 de junio de 1918, respectivamente. 
nueva comandancia general en el recién creado Protectorado de Marruecos, con cabecera en Larache ${ }^{26}$.

La columna vertebral operativa del ejército era la división. Salvo alguna pequeña alteración, en vísperas de Annual las ocho regiones peninsulares estaban guarnecidas por catorce divisiones de infantería de línea y tres de cazadores, una división y tres brigadas de caballería, y unas cincuenta pequeñas unidades independientes adscritas a la reserva general: regimientos de alta montaña, de cazadores de caballería, de artillería de costa, de transmisiones, de pontoneros y de ferrocarriles, y batallones de artillería antiaérea y de aviación. Las divisiones encuadraban dos brigadas de dos regimientos de infantería, otro de artillería a pie (montado en la de caballería), un batallón de zapadores minadores, una compañía de intendencia y otra de sanidad. Aparte, en Baleares y Canarias había otras dos divisiones, y en Ceuta y Melilla, dos brigadas, en ambos casos, reforzadas con tropas de las otras $\operatorname{armas}^{27}$.

Aunque estas cifras puedan dar la sensación de que España mantenía un ejército desmesurado para un país carente de amenazas externas, la realidad era muy distinta. La plantilla de los regimientos de infantería, que constituían el grueso de la fuerza disponible, establecía que cada uno de ellos encuadrara unos 80 oficiales y 1.200 clases de tropa. Sin embargo, aunque los cuadros de mando solían estar al completo, los efectivos de tropa rara vez alcanzaban la mitad de lo previsto. Por otra parte, su nivel de instrucción era muy deficiente, debido entre otras cosas a que los cuarteles estaban en el centro de las ciudades y a la carencia de campos de tiro y de maniobras. Y para más inri, las compañías debían aportar el personal para los múltiples servicios de custodia y mantenimiento de los cuarteles, lo cual, sumado a las ausencias por permiso y enfermedad, hacía que no fuese inusitado que una compañía se encontrase con solo dos o tres hombres disponibles para la instrucción diaria ${ }^{28}$.

La triste realidad era que la única razón de existir de muchas unidades no era otra que acomodar al desmesurado número de cuadros de mando, muchos de los cuales estaban desencantados con su profesión y tenían escasas expectativas de promoción: "la mayor parte del cuerpo de oficiales dejó de amar la guerra -razón principal de su existencia- e insensiblemente llegó al convencimiento de que su misión no era otra que vegetar tranquilamente en las guarniciones -cuando no en destinos sedentarios- formando parte de la complicada y abundante burocracia

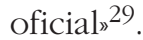

26. Puell de la Villa, Fernando: Historia del Ejército en España, 2. ${ }^{a}$ ed. Madrid: Alianza, 2019, pp. $123-124$.

27. Anuario Militar de España. Madrid: Depósito de la Guerra, 1909.

28. Gallego: Op. cit., 1905, p. 32.

29. Mola VIDal, Emilio: «El pasado, Azaña y el porvenir». En: Obras completas. Valladolid: Santarén, 1940, p. 946. 


\subsection{El ejército colonial}

A partir del establecimiento del Protectorado de Marruecos en 1912 y de los distintos ciclos de operaciones desarrollados en aquel territorio, el pomposamente titulado "Ejército de África" se incrementó notablemente, unas veces ubicando en él unidades peninsulares completas o trasladando fuerzas expedicionarias en otras, detraídas habitualmente de diversas guarniciones peninsulares. Aunque nunca llegó a cuajar el intento de constituir un ejército colonial, similar a los mantenidos por Francia y el Reino Unido, sí se impulsó la recluta de indígenas para reducir la factura en sangre española que aquella guerra se cobraba y que tanto malestar social generaba, llegando en casos a tener consecuencias tan graves como las de la Semana Trágica barcelonesa de julio de $1909^{30}$.

A partir de los incidentes melillenses de 1893, se comenzó a reforzar la guarnición de las plazas de soberanía, hasta entonces llamadas presidios, en las que las únicas tropas permanentes eran las disciplinarias. Ceuta se guarneció con dos Regimientos de Infantería y se organizó la Milicia Voluntaria, compuesta por la Compañía de Moros Tiradores del Rif y una Compañía de Mar. Y Melilla, aparte del tradicional Batallón Disciplinario, con otros dos Regimientos de Infantería y una Compañía de Mar. No obstante, estas unidades demostraron ser insuficientes en 1909 para proteger las concesiones mineras en los alrededores de esta última ciudad, cuando las cabilas comenzaron a dificultar los trabajos. El general Marina pidió refuerzos y el presidente Maura ordenó movilizar varios batallones de cazadores para trasladarlos a Melilla.

Marina llegó a tener bajo su mando 45.000 hombres y, en enero de 1910, se dieron por finalizadas las operaciones. Melilla obtuvo rango de Capitanía General y su guarnición permanente se elevó a los 20.000 soldados. En el verano de 1911, El Mizzian proclamó la guerra santa contra los españoles y se reprodujeron los combates al oeste de la plaza. Las principales consecuencias de estas campañas, derivadas de la muerte de unos 4.000 hombres en unos cuantos meses de combates, y de las airadas manifestaciones antiquintas provocadas por las movilizaciones de reservistas, fueron la abolición de las injusticias en la prestación del servicio militar y la creación de unidades indígenas en Marruecos ${ }^{31}$.

La primera unidad de esta naturaleza había sido la Policía Indígena, constituida en 1908 con el propósito de ampliar la influencia española en torno a Melilla. Su organización se basaba en la mía (compañía), con efectivos de algo más de

30. Sobre los intentos de organizar un ejército colonial, vid. Bru SÁNCHEZ-ForTún, Alberto y MESA GutiérRez, José Luis de: "El debate sobre el ejército colonial en España, 1909-1914”, Revista de Historia Militar, 112, 2012, pp. 65-124.

31. Sobre la organización de las unidades indígenas, vid. Ramos Winthuyssen, Javier: Tropas indigenas y Ejército colonial. Sevilla: Imp. de Gómez Hnos., 1921; SотTO MonTEs, Joaquín de: "Notas para la historia de las fuerzas indígenas del antiguo Protectorado de España en Marruecos", Revista de Historia Militar, 35, 1973, pp. 117-154; y MADARIAGA, Rosa María de: Los moros que trajo Franco... La intervención de tropas coloniales en la Guerra Civil española. Barcelona: Martínez Roca, 2002, pp. 75-86 y 104-109. 
un centenar de hombres. Su número aumentó a medida que lo hacía el territorio sometido, llegando a haber 30 mías en 1921. Aunque su misión básica era de carácter policial, podían ser, y en realidad lo eran, empleadas en operaciones militares. Como su labor requería un buen conocimiento del terreno y de las gentes locales, el personal era reclutado en el área de actuación de cada mía. El mando lo ejercían oficiales españoles, secundados por algún nativo. En 1919, las mías fueron clasificadas en tres categorías: de Contacto, llamadas así las que operaban en zonas en proceso de pacificación; de Apoyo, las que lo hacían en zonas recientemente pacificadas, y de Retaguardia, desplegadas en las zonas totalmente sometidas ${ }^{32}$.

En junio de 1911 se organizó el Grupo de Fuerzas Regulares de Melilla, formado por marroquíes voluntarios de las cabilas rivales de El Mizzian, puestos bajo el mando de oficiales españoles. La decisión fue muy acertada en relación al reclutamiento metropolitano y muy eficaz para la lucha irregular que caracterizaba aquel tipo de operaciones. Así, al convertirse el territorio en Protectorado y alzarse en armas El Raisuni en la Yebala, las tropas indígenas se mostraron mucho más efectivas que las peninsulares. En 1913 también se creó la Mehal-la Jalifiana, de entidad similar a la de un batallón, que simultaneaba la misión de proteger al jalifa con la participación en las operaciones.

En 1914, Echagüe creó tres nuevos Grupos de Regulares en Ceuta, Tetuán y Larache y fijó la composición y plantilla que perduraban en 1921. Cada Grupo estaba compuesto por dos tabores de infantería y uno de caballería, de entidad similar a la de un batallón; la tropa podía ser oriunda de cualquier cabila, pero la mitad de los suboficiales debía ser personal voluntario español y también debían serlo todos los oficiales, salvo algunos subalternos nativos ${ }^{33}$. En 1917, cuando se reorganizó el Ejército de África, se dio absoluta prioridad a las tropas indígenas y, poco a poco, el número de tabores de infantería fue aumentando, e incluso se dotó a cada uno de ellos con una compañía de ametralladoras en 1919.

Las harcas también eran unidades nutridas por nativos, pero tenían carácter irregular y se creaban de forma temporal para operaciones concretas, siendo desmovilizadas al finalizar estas, aunque algunas alcanzaron un alto grado de continuidad. Reclutadas normalmente en una misma cabila, podían estar dirigidas tanto por sus propios líderes como por mandos españoles procedentes de Regulares. Cada harca tomaba el nombre de su jefe o el de la cabila en que se formaba. Sus efectivos podían variar desde un centenar de hombres a más de un millar. Inicialmente, eran poco más que bandas armadas en cuanto a organización y disciplina, por lo que se empleaban preferentemente en misiones de reconocimiento y cobertura a vanguardia de las columnas y en razias contra poblados hostiles.

En 1921, el Ejército de África estaba compuesto por seis Regimientos de Infantería de Línea, doce Batallones de Cazadores, tres Regimientos de Caballería,

32. Mesa Gutiérrez, José Luis de: La Policía Indígena española. Murcia: Fajardo el Bravo, 2018.

33. Real Orden Circular de 31 de julio de 1914: Colección Legislativa del Ejército (en notas sucesivas CLE), 1914, n. $^{\circ} 135$. 
dos Regimientos Mixtos de Artillería, cuatro Grupos de Regulares Indígenas y la Mehal-la Jalifiana, cuyos efectivos nutrían las columnas que protagonizaron las operaciones desarrolladas en las zonas del Rif y de la Yebala ${ }^{34}$. En septiembre del año anterior, se creó una nueva unidad, que recibió el nombre de Tercio de Extranjeros y pretendía ser el equivalente de la Legión Extranjera francesa, aunque casi todos los alistados fuesen de nacionalidad española ${ }^{35}$.

\section{El CUERPO DE OfiCIALES}

Los militares profesionales, que junto con la pequeña burguesía habían abanderado la revolución liberal durante el reinado de Isabel II, se replegaron hacia el conservadurismo en las ideas y hacia el reaccionarismo en las actitudes sociales en época de la Restauración ${ }^{36}$. Y a cambio del compromiso de desentenderse de la política, adquirieron el monopolio de la gestión militar y convirtieron la institución castrense en un coto cerrado que no admitía interferencias del gobierno. La Ley Constitutiva del Ejército de 1878 y su Adicional de 1889 les encomendó la garantía del orden constitucional, pero no atribuyó a ningún organismo la evaluación de las posibles contingencias justificativas de una intervención militar, ni designó a la autoridad responsable de tomar la iniciativa para que la fuerza armada actuara. Simultáneamente, se desarrolló un complejo entramado burocrático que, a la vez que permitía la autosuficiencia del ejército en todos los campos -del jurídico al docente y de la panificación a la farmacia-, permitía asegurar puestos de trabajo a gran número de oficiales.

A comienzos del siglo xx, la oficialidad pasó del conservadurismo político al reaccionarismo ideológico -en un segundo repliegue corporativo-, como respuesta a su subjetiva apreciación de que los políticos y la opinión pública eran injustos al atribuirles la total responsabilidad del desastre ultramarino, llegando a acusarles colectivamente de tibieza frente al enemigo. Sus bochornosos asaltos a la redacción de algunos periódicos y su injustificable presión sobre el gobierno para hacerse con el control judicial de los delitos de opinión, solo pueden llegar a entenderse teniéndose en cuenta que aquellos hombres llevaban combatiendo muchos meses en la adversa geografía tropical, que habían estado al borde de

34. Pérez Fernández-Turégano, Carlos: «La Alta Comisaría de España en Marruecos: estudio institucional y prosopográfico». En: Javier Alvarado Planas y Juan Carlos Domínguez Nafría (dirs), La Administración del Protectorado Español en Marruecos. Madrid: Centro de Estudios Políticos y Constitucionales, 2014, cap. vi.

35. En 1922, el 83,58 por ciento de los alistados eran españoles, seguidos muy de lejos por el 2,87 por ciento de portugueses: Ballenilla García de Gamarra, Luis: La Legión, 1920-1927. La creación de una unidad colonial. Murcia: Fajardo el Bravo, 2010, anexo A, documento 5.

36. GonZÁlez-Pola de la GRANJA, Pablo: La configuración de la mentalidad militar contemporánea (1868-1909): del Sexenio Revolucionario a la Semana Trágica. Madrid: Ministerio de Defensa, 2003. 
acabar con las insurrecciones cubana y filipina, y que las tropas estadounidenses no habían sido capaces de derrotarles en el campo de batalla ${ }^{37}$.

La carrera de la oficialidad durante esta época se vio muy afectada por su macrocefalia. La causa de este endémico fenómeno era que, si bien resultaba relativamente sencillo satisfacer la demanda de nuevos oficiales durante un conflicto bélico, llegada la paz resultaba mucho más fácil despedir a la tropa que a sus mandos. Sin dejar de tener en cuenta el legítimo deseo de cualquier militar de seguir su vocación castrense, diversos factores socio-económicos -pocas alternativas laborales atractivas en el ámbito civil, la costumbre de considerar aquella profesión como un medio de ascenso social o la seguridad salarial como funcionarios del Estado- contribuían a que fuesen muy reacios a dejar prematuramente el servicio activo y, dado el peso -manifiesto o latente- que tenían los militares en la vida política, los gobiernos no podían o no se atrevían a imponer medidas enérgicas para eliminar o reducir el excedente de mandos ${ }^{38}$.

\subsection{La carrera militar}

La mayor parte de los oficiales que combatieron en Marruecos se habían formado con el plan de estudios implantado por el general López Domínguez en 1893, que se mantuvo vigente hasta $1927^{39}$. Su reforma clausuró la Academia General Militar establecida en Toledo diez años antes y restauró las academias específicas para cada arma: Infantería en Toledo, Caballería en Valladolid, Artillería en Segovia e Ingenieros en Guadalajara. El ingreso se hacía por oposición en cada una de ellas y el plan de estudios duraba tres años en las Armas Generales (Infantería y Caballería), y cinco en los Cuerpos Facultativos (Artillería e Ingenieros). En estos últimos, los alumnos recibían una excelente formación científica y técnica al objeto de capacitarlos para ocupar destinos en las fábricas e industrias militares o elaborar todo tipo de proyectos arquitectónicos y viarios, además de terminar su carrera con la titulación civil de ingeniero industrial o de ingeniero de caminos. La diferencia cuantitativa y cualitativa en la formación básica de los cuadros de mando sería una continua fuente de problemas y disfunciones durante este periodo.

Aquel currículo fue objeto de muchas críticas. Entre los aspectos más controvertidos, destacaban los ataques a su excesivo contenido técnico-científico y

37. Espadas Burgos, Manuel: "El factor ultramarino en la formación de la mentalidad militar", Estudios de Historia Social, 1-4, 1988, pp. 311-325.

38. Herrero: Op. cit., 2017, caps. 1 y 5.

39. Sobre la enseñanza militar en el periodo de las campañas marroquíes, vid. IsABEl SánCHEz, José Luis: "La formación de los oficiales de Infantería entre 1909 y 1921». En: ARAGÓn REYES, Manuel (dir.): El Protectorado español en Marruecos: la historia trascendida. Bilbao: Iberdrola, 2013, v. III, pp. 324-348, y Guerrero Martín, Alberto: "La enseñanza para la formación de oficiales durante el primer tercio del siglo xX", Revista de Historia Militar, 121, 2017, pp. 53-61. 
teórico, basado en la memorización libresca, en detrimento de una formación más práctica, más orientada hacia los cometidos castrenses del oficial subalterno ${ }^{40}$.

Como reacción a esas críticas y a las recientes experiencias bélicas en Melilla, en el bienio 1911-1913 se intentaron corregir algunas deficiencias. En esa línea, se reformaron los procedimientos de selección para el ingreso en las academias y la metodología de la enseñanza impartida en ellas.

Otro rasgo singular de aquel currículo, común a todos los ejércitos europeos de la época, era que la asignatura de táctica únicamente prestaba atención a la guerra regular, es decir, a la librada entre dos ejércitos similares que combatían con arreglo a la doctrina imperante en Europa, y ninguna a la entonces denominada guerra de guerrillas, que hoy llamaríamos guerra irregular o guerra híbrida. Sorprende el desmedido interés por estudiar e intentar extraer conclusiones de la Guerra Franco-Prusiana o de la Ruso-Japonesa en un ejército cuyas últimas experiencias bélicas se habían caracterizado por su irregularidad, tanto en el escenario peninsular como en el ultramarino. En su descargo, cabría decir que tampoco en Sandhurst se prestaba atención alguna a la Guerra de los Boers ni a los descalabros sufridos en Afganistán, en la India, en Sudán y en Zululandia. La obsesión por las maniobras magistrales y por las batallas decisivas hacía que, mientras en Marruecos comenzaba a librarse una nueva guerra netamente irregular, se hubiesen olvidado totalmente las lecciones aprendidas en Cuba y Filipinas, de las cuales no quedaba rastro alguno en aquellos planes de estudio ${ }^{41}$.

Una vez egresados de la academia, con el empleo de segundo teniente en las Armas Generales y con el de teniente en los Cuerpos Facultativos, los flamantes oficiales percibían sueldos realmente modestos, apenas por encima de los de un obrero especializado $^{42}$. Sin embargo, debido a lo abultado de los escalafones, los gastos salariales desequilibraban totalmente el presupuesto militar. Para hacerse una idea del problema, casi dos tercios se dedicaban a cubrir una partida que en Alemania y en Francia apenas alcanzaba el 20 por ciento.

Y aunque las quejas fueran frecuentes, el excesivo número de oficiales impedía poder mejorar sus sueldos: entre 1900 y 1936, el único aumento salarial significativo se produjo en 1918. Ante tal panorama, no pocos oficiales complementaban sus ingresos con una segunda ocupación en el ámbito civil, en la que a veces acababan poniendo más celo que en su quehacer castrense. Y no debe sorprender que otros decidiesen impulsar su carrera en Marruecos, ya fuese por la vía del ascenso por méritos de guerra, con el consiguiente aumento de retribuciones, o por la de obtener alguna de las condecoraciones que llevaban aparejada una pensión vitalicia: cruz laureada de San Fernando, medalla militar individual o

40. Herrero: Op. cit., 2017, pp. 34-38.

41. SтUскі, Andreas: Las guerras de Cuba: violencia y campos de concentración (1868-1898). Madrid: La Esfera de los Libros, 2017, pp. 48-50 y 215.

42. SAN MARTÍN LOSADA, Eduardo: Sueldos, haberes y gratificaciones del personal del Ejército. Madrid: Imp. del Patronato de Huérfanos de Intendencia e Intervención Militares, 1922. 
cruz del Mérito Militar con distintivo rojo, respectivamente pensionadas con el 50, el 20 y el 10 por ciento del sueldo ${ }^{43}$.

Lógicamente, lo que se dedicaba a costes de personal iba en perjuicio de los gastos en instrucción, armamento, equipamiento e infraestructuras, lo que se reflejaba a menudo en que los planes de modernización se implementaran con desesperante parsimonia. Las limitaciones presupuestarias eran también la causa de la escasez de grandes maniobras y de lugares adecuados para poder realizarlas, o de que la proporción entre el número de efectivos y el de piezas de artillería fuese una de las más bajas de Europa. Por ejemplo, en 1909, mientras que en España la citada proporción era de 3,9 por cada mil hombres, la de otros países con menor peso específico era bastante superior: Bulgaria, 4,6; Portugal, 5.0, o Grecia, 6.9 ${ }^{44}$.

\subsection{La promoción y la asignación de destinos}

Aquel estado de cosas también repercutía en las expectativas de poder promocionar, particularmente desde que, al término de las campañas de Cuba y Filipinas, se decidió amortizar la mitad de las vacantes que se produjeran en el generalato y un cuarto en la oficialidad ${ }^{45}$. Además la llamada "escala cerrada», es decir, el ascenso por rigurosa antigüedad en el empleo, era la única vía de promoción en tiempo de paz desde 1889, lo que acarreaba una sobresaturación de mandos intermedios, obligando además a crear una inmensa superestructura burocrática para mantenerlos ocupados y que más de la mitad de los 536 generales y 23.940 oficiales existentes en 1909 vivieran al margen de unas unidades donde vegetaban menos de 80.000 soldados: "Causa profunda pena, que hace decaer el espíritu militar y el amor al servicio, el ver esos batallones y regimientos en cuadro; [...] esos regimientos de reserva sin personal alguno de tropa, sólo nutridos por un contingente excesivo de jefes y oficiales que a nada responden " ${ }^{46}$.

La situación expuesta afectó especialmente al Arma de Infantería. Los aproximadamente dos mil oficiales existentes hacia 1830 se habían multiplicado por seis en 1912, en tanto que el número de soldados en filas solo había pasado de 50.000 a 57.600, con la consecuencia de que el 60 por ciento de los coroneles, el 50 de los tenientes coroneles, el 75 de los comandantes, el 50 de los capitanes, el 30 de los tenientes y el 50 de los segundos tenientes permanecieran en las situaciones

43. Reales Decretos de 18 de febrero de 1891 y de 10 de marzo de 1920: GM, 20 de febrero de 1891 y 14 de marzo de 1920, respectivamente.

44. Vigón Suerodíaz, Jorge: Historia de la artillería española. Madrid: Ministerio de Defensa, 2014, v. II, p. 299, nota 215.

45. Para todo lo relacionado con ascensos y destinos de la oficialidad durante el primer tercio del siglo xx, vid. Albaladejo Asensio, María Isabel: La evolución de los sistemas de ascenso y de provisión de destinos en el Ejército. Tesis doctoral inédita. Universidad Nacional de Educación a Distancia, 2015, cap. 3 .

46. Canella Secades, Francisco de Borja: Algo sobre la reorganización del Ejército. Córdoba: Imp. del Diario de Córdoba, 1904, p. 6. 
de reemplazo o de reserva u ocuparan destinos, más o menos burocráticos, pero siempre sin tropas bajo su mando ${ }^{47}$.

Como antes se ha apuntado, la única salida para quienes no se resignaban a una carrera gris era el ascenso por méritos de guerra y, al haberse producido tantas irregularidades en su concesión, muchos recelaban profundamente de la ecuanimidad del sistema. Aunque se habían tomado medidas para concederlos con más rigor, su reintroducción en las campañas marroquíes avivó de nuevo las sospechas de favoritismo, pues quien más parecía beneficiarse de ellos era el grupo relativamente limitado destinado en las unidades indígenas y que acabaron siendo conocidos como «africanistas» ${ }^{48}$.

Como se ha anticipado, en 1889 se estableció que solo se podría ascender en tiempo de paz con ocasión de vacante - por rigurosa antigüedad hasta el empleo de coronel y por elección, a general- y que, en el de guerra, se pudieran conceder ascensos cuando concurrieran circunstancias excepcionales de valor y merecimientos en un determinado individuo ${ }^{49}$. La norma, aplicable tanto a los oficiales de las Armas Generales como a los de los Cuerpos Facultativos, vulneraba la tradición de que estos ascendiesen únicamente por antigüedad, por lo que se les autorizó a permutar el ascenso por méritos de guerra por una condecoración pensionada, autorización que eliminó Primo de Rivera y que dio origen a su enfrentamiento con el Cuerpo de Artillería en los años finales de la Dictadura ${ }^{50}$.

Tras la pérdida de Cuba y Filipinas, se suspendieron los ascensos por méritos de guerra, sin duda concedidos con excesiva prodigalidad, pero en 1910 Luque los volvió a implantar para recompensar a los oficiales que habían combatido el año anterior en Melilla y también con la idea de favorecer la afluencia de voluntarios para la recién iniciada Campaña del Kert ${ }^{51}$. El reparto de ascensos y condecoraciones fue muy controvertido, pues se premió más a quienes tenían conexiones con el poder que el mérito personal y profesional. Tampoco se logró inicialmente que afluyeran voluntarios a Marruecos, pese a los sustanciosos complementos de sueldo que cobraban los destinados en Ceuta y Melilla desde $1908^{52}$. Pero cuando comenzó a trascender que allí se podían hacer carreras fulgurantes con relativa

47. Puell de la Villa, Fernando: El soldado desconocido: de la leva a la mili (1700-1912). Madrid: Biblioteca Nueva, 1996, pp. 238-241.

48. Sobre los africanistas, vid. Mas ChaO, Andrés: La formación de la conciencia africanista en el ejército español (1909-1926). Madrid: Servicio Geográfico del Ejército, 1988; Balfour, Sebastian: Abrazo mortal. De la guerra colonial a la guerra civil en España y Marruecos (1909-1939). Barcelona: Península, 2002, 2. ${ }^{a}$ parte, cap. 2; MAdARIAGA, Rosa María de: Los moros que trajo Franco... La intervención de tropas coloniales en la Guerra Civil española. Barcelona: Martínez Roca, 2002, pp. 32-47, y Macías Fernández, Daniel: Franco "nació en África". Los africanistas y las Campañas de Marruecos. Madrid: Tecnos, 2019.

49. Ley Adicional a la Constitutiva del Ejército, 19 de julio de 1889: GM, 20 de julio de 1889

50. Puell de la Villa, Fernando: «La cuestión artillera», Hispania, 165, 1987, pp. 279-308.

51. Alonso IBÁÑEZ, Ana Isabel: Las Juntas de Defensa Militares. Madrid: Ministerio de Defensa, 2004, p. 56.

52. Real Orden Circular de 21 de febrero de 1908: CLE, 1908, n. $^{\circ} 7$. 
facilidad, la situación revirtió y se hizo muy difícil obtener destino en aquellas guarniciones sin estar muy bien recomendado.

La necesidad de agenciarse una recomendación para obtener el destino apetecido obedecía a la arbitraria normativa que regulaba su adjudicación, pues la Ley Constitutiva del Ejército de 1878 había establecido que, si bien el empleo era «una propiedad con todos los derechos y goces que las leyes y reglamentos consignan" y ningún oficial podía ser desposeído del mismo salvo por sentencia judicial, el destino era de la "libre voluntad del Rey a propuesta de su Ministro responsable» 53 .

Aunque tanto Luque como Echagüe intentaron paliar el descontento que esta cuestión ocasionaba, aquel fue creciendo hasta eclosionar en la crisis de las Juntas de Defensa. Sin embargo, cuando en el Ministerio de la Guerra ya se conocía que se estaban incoando, se decidió solucionar al menos el que originaba la arbitraria provisión de destinos. A tal efecto, en mayo de 1917, el general Aguilera, ministro de la Guerra del gobierno de García Prieto, firmó la norma que regularía la adjudicación de los destinos militares nada menos que hasta 1989 y que inspiraría toda la normativa relacionada con esta cuestión en los diversos cuerpos funcionariales de la Administración General del Estado hasta el día de hoy.

La citada norma establecía que las vacantes que se produjeran en cualquier unidad o dependencia militar debían ser anunciadas en el Diario Oficial del Ministerio de la Guerra, pudiendo ser solicitadas en un determinado plazo de tiempo por cuantos oficiales cumpliesen las condiciones requeridas y que su adjudicación se haría por riguroso orden de antigüedad en el empleo de los peticionarios. Esta regla general tenía dos excepciones: las vacantes de profesorado y del EMC se adjudicarían por concurso de méritos, basado en un baremo específico al que se daría publicidad, y por libre designación del ministro de la Guerra, las de los considerados puestos de confianza: Casa del Rey, Secretaría del Ministro, jefes de unidad armada independiente, agregados militares y ayudantes de campo ${ }^{54}$.

El 1 de junio de 1917, solo dos días después de que se resolviese este asunto, en plena Primera Guerra Mundial y mientras en Marruecos se estaba combatiendo, se produjo la primera intervención de carácter corporativo del ejército español, intervención que torció el rumbo de la institución e inauguró un largo período militarista ${ }^{55}$. La crisis de 1917 demostró, además, que el régimen canovista era un instrumento obsoleto e inservible, que los partidos catalanista y socialista habían alcanzado la mayoría de edad, y que ambos estaban decididos a intervenir activa y decisivamente en la política nacional.

53. Ley Constitutiva del Ejército, 29 de noviembre de 1878, art. 30: GM, 30 de noviembre de 1878.

54. Puell de la Villa, Fernando: "Evolución de los sistemas de ascensos y destinos de la oficialidad española". En: Les armées espagnoles et françaises. Modernisation et réforme entre les deux Guerres Mondiales, Annexes aux Melanges de la Casa de Velázquez. Madrid: Casa de Velázquez, 1989, pp. $170-176$.

55. Sobre la génesis, desarrollo y desenlace de las Juntas de Defensa, vid. Alonso: Op. cit., 2004. 
La causa primigenia de la aparición de las Juntas de Defensa fueron los privilegios económicos y profesionales obtenidos por la oficialidad que combatía en Marruecos ${ }^{56}$. A consecuencia de ello, el ejército se dividió, abriéndose una brecha entre los llamados "africanistas" y los que estaban destinados en las unidades peninsulares que, mayoritariamente adheridos a las Juntas, recibieron el apelativo de «junteros». Cuestionada por ambos grupos, existía otra facción, los denominados "palatinos", cuya estrecha relación con el monarca era recompensada con prebendas y condecoraciones, pese a sus muy discutibles méritos profesionales, y que además tenían bastante expedita la senda hacia el generalato.

El antagonismo entre peninsulares y africanistas alcanzaría su apogeo cuando Luque impuso las pruebas de aptitud para el ascenso; eclosionó en junio de 1917 y no se resolvió hasta 1922, en parte debido a la catástrofe de Annual. Muchos meses antes de que trascendiera a la opinión pública la existencia de las Juntas de Defensa, el ministro de la Guerra tenía conocimiento de que se estaban organizando en Barcelona, siendo toleradas sus actividades e incluso escuchadas sus demandas con cierta comprensión en la Corte y en el Ministerio. No obstante, sus desmesuradas demandas, presentadas de tal forma que vulneraban abiertamente la disciplina al descalificar al propio ministro, obligaron a detener y encausar a sus promotores. Pero al solidarizarse con ellos la práctica totalidad de la oficialidad peninsular, el gobierno cedió y los puso en libertad. Aquellos se crecieron y llevaron sus pretensiones a extremos que de ninguna manera podían ser aceptables, lo que provocó tres crisis sucesivas de gobierno, hasta forzar a la Corona a solicitar el apoyo de las diversas fuerzas políticas para que uno de concentración solucionara el problema. Este entró en vías de solución al decretarse la suspensión de los ascensos por méritos de guerra a comienzos de 1918, lo que supuso un duro revés para los africanistas, que se vieron privados de lo que consideraban su derecho a ser legítimamente recompensados por los riesgos y penalidades a los que se exponían.

\subsection{La operatividad de las unidades destacadas al Protectorado}

La forma de combatir de los rifeños desconcertó durante bastante tiempo a los responsables de conducir las operaciones en Marruecos, cuya única experiencia bélica la habían adquirido en Cuba y Filipinas, también contra un enemigo irregular, pero de rasgos muy distintos y en un terreno totalmente diferente -una estrecha franja de unos 20.000 kilómetros cuadrados, muy abrupta, sin vías de comunicación ni núcleos de población importantes-, y formados académicamente conforme a los estándares de la guerra convencional practicada en Europa. En Marruecos no era posible compartimentar el territorio, como se hizo en Cuba, ni

56. BRu SÁnchez-Fortún, Alberto: "Los ascensos de guerra: su repercusión en el nacimiento y desarrollo de las Juntas de Defensa", Revista de Historia Militar, 119, 2016, pp. 13-66. 
separar a la población afecta de la insurrecta, pues era difícil precisar el grado de lealtad de cada cabileño.

Además, su forma de combatir, de carácter individualista y basada en la movilidad y en el conocimiento del terreno, tenía tres principales variantes: simular repliegues para separar del grueso a alguna unidad y caer sobre ella después; emboscar a las que prestaban apoyo logístico, y hostigar a las que estaban en marcha o acampadas mediante el sistema de "pacos", francotiradores emboscados que causaban cientos de bajas. La capacidad de los cabileños para infiltrarse y emboscarse impedía maniobrar con soltura y exigía controlar el territorio mediante una red de posiciones fortificadas bien guarnecidas, que en realidad solo dominaban su campo de tiro. Además, su logística era elemental - «llevaban la intendencia en la capucha de sus chilabas, ${ }^{57}$ - y su resiliencia, muy superior a la de unas tropas necesitadas de todo tipo de servicios para poder moverse, abastecerse y recuperarse de sus heridas y enfermedades.

Ante esta situación, el general Berenguer llegó a la conclusión de que era necesario adecuar los procedimientos tácticos tradicionales a la situación con la que se enfrentaban - «renunciar a ellos es abdicar de las ventajas del arte y de la inteligencia cultivadas ${ }^{58}$ - y encuadrar las tropas en una o varias columnas a las que marcar objetivos claramente delimitados, al objeto de que, desde ellos y una vez bien asegurados mediante una línea de puestos fortificados, pudieran emprenderse nuevas acciones sobre otros, de forma que se fuera controlando paulatinamente el territorio. Esta forma de conducir las operaciones, llamada de "mancha de aceite», había sido forjada por el mariscal Lyautey y se empleó por primera vez en el bienio 1919-1921, con éxito en la zona occidental del Protectorado y todo lo contrario en la oriental, donde, mal aplicada y con objetivos demasiado ambiciosos, condujo al desastre de Annual.

\section{LA TROPA}

El servicio militar se universalizó en 1912, al eliminarse la redención en metálico y la sustitución, procedimientos que eximían de quintas a los hijos de familias pudientes. Aunque estos siguieron exentos de hacer vida cuartelera gracias al pago de una cuota, empezaron a compartir instrucción, servicios y locales de trabajo con los que procedían del proletariado. Sin embargo, la inmensa mayoría de los soldados continuó caracterizándose por su baja extracción social, alta tasa de analfabetismo, escasísimo nivel de instrucción y, como novedad, por adoptar comportamientos y actitudes cada vez más similares a las mantenidas por su grupo social de procedencia.

57. Berenguer, Dámaso: La guerra en Marruecos. Ensayo de una adaptación táctica. Madrid: Fernando Fe, 1918, pp. 33-34.

58. Ibidem, p. 13. 


\subsection{Rasgos sociales}

Durante este periodo, la población española rondó los veinte millones, de los que menos de la mitad eran hombres con una esperanza de vida asombrosamente baja: 27,04 años. Además, la población era muy joven: unos cinco millones no llegaban a los veinticinco años, algo menos de tres tenía entre veinticinco y cincuenta, y solo un millón y medio más de cincuenta ${ }^{59}$. Entre 1912 y 1921, alrededor de millón y medio de jóvenes fueron llamados a filas, pero un tercio de ellos no llegó a pisar el cuartel por haber sido declarado inútil para el servicio, debido a medir menos de 1,54 metros o presentar algún defecto físico. Y otros mil muchachos, en edades comprendidas entre los veinte y los veintidós años, morían cada año mientras prestaban su servicio militar y cinco mil más no podían reincorporarse al trabajo cuando se licenciaban. Resulta bochornoso comparar estos datos con los de otros países europeos y constatar que, mientras en España morían quince de cada mil hospitalizados, solo un soldado alemán fallecía en las mismas circunstancias o que la cifra de no aptos para el servicio estuviera dos veces y media por encima de las de Francia e Italia ${ }^{60}$.

El éxodo del campo a la ciudad y el fenómeno migratorio ultramarino ejercieron gran influencia sobre el reclutamiento. Se calcula que cerca de 26.000 campesinos abandonaron cada año su aldea entre 1910 y 1920 para establecerse en una ciudad o pueblo importante, con lo que el número de los de más diez mil habitantes pasó de 169 a 234; con más de cincuenta mil, de 17 a 22; con más de cien mil, de ocho a once, y dos sobrepasaron por primera vez el medio millón. El establecimiento de los futuros soldados en los míseros cinturones que iban creciendo alrededor de las grandes ciudades, sometidos a la influencia de la propaganda anarquista o socialista y en contacto cotidiano con los lujosos barrios residenciales de los ensanches urbanos, modificó sensiblemente la resignada actitud que hasta entonces habían mantenido cuando se incorporaban a filas desde un entorno rural.

Los que se decidían a emigrar a Sudamérica -cerca de un millón de jóvenes entre 1900 y $1920^{61}$ - lo hacían obligados por un futuro sin esperanza y no para eludir sus deberes militares. Pero tomada esa determinación, era habitual que emprendieran viaje antes de su alistamiento o, más menudo, a raíz de recibir el aviso municipal de haber entrado en edad de quintas, suficiente acicate para no posponer por más tiempo una idea más o menos acariciada de antemano.

59. Censo de la población de España, según el empadronamiento becho en la Península e Islas adyacentes el 31 de diciembre de 1910. Madrid: Instituto Geográfico y Estadístico, 1913, pp. 402-403.

60. Fernández de Alcalde, Dionisio A.: Procedimientos médico-legales para evitar la tuberculosis en el Ejército. Ponencia presentada al 1.er Congreso Nacional contra la Tuberculosis. Valladolid: Imp. de Julián Torés, 1908, p. 4, y GonzÁlez Deleito, Federico: Enseñanzas médico-militares de la actual campaña. I. El reclutamiento. Madrid: Imp. de Valentín Tordesillas, 1920, pp. 9-12, 24-25 y 44-45.

61. SÁnchez Jiménez, José: "La población, el campo y las ciudades». En: José María Jover Zamora (dir.), Historia de España Menéndez Pidal. Los comienzos del siglo xx. La población, la economía, la sociedad, 1898-1931. Madrid: Espasa-Calpe, 1992, t. 37, p. 275. 
Pese al crecimiento urbano, la inmensa mayoría de los soldados continuó procediendo del medio rural -campesinos asalariados o hijos de pequeños propietarios y arrendatarios- y muchos llegaban a los cuarteles sin haber pisado jamás una escuela, al haber comenzado a trabajar la tierra desde niños, cuando no permanecido aislados en los montes a cargo de un hato de ganado. Pero también comenzó a entrar en filas un número significativo y progresivamente creciente de obreros y albañiles, así como de trabajadores del sector servicios, todos ellos mejor formados que los anteriores gracias a que en las ciudades había más escuelas que en las aldeas. No obstante, al no estar dimensionadas para acoger a aquella avalancha de niños, anarquistas y socialistas se afanaron por escolarizar a los hijos del proletariado, al igual que la Iglesia católica hacía respecto a los de la burguesía. A consecuencia de ello, se alzaron voces en el ejército para señalar el riesgo que entrañaba para la supervivencia del régimen encomendar su defensa a unos soldados más proclives a identificarse con los planteamientos revolucionarios que con los de la tradición liberal-burguesa ${ }^{62}$.

\subsection{El servicio militar}

El sistema de reclutamiento instaurado por la Revolución Francesa, vigente en España desde 1812, proporcionaba cada año por sorteo unos 25.000 hombres para reemplazar a los que se reintegraban a sus hogares tras permanecer en el cuartel ocho años. Este sistema preveía que los hijos de las familias pudientes se libraran de ser alistados mediante el pago de una importante cantidad de dinero al Tesoro, procedimiento denominado redención en metálico, o pagando a un sustituto que ocupara su lugar cuando fueran llamados a filas. Sin embargo, por influencia prusiana, a comienzos del siglo xx la mayoría de los países sustituyó ese sistema por otro, consistente en alistar a cuantos cumplieran veinte años sin excepción alguna, instruirlos durante tres años y devolverlos a sus casas en situación de reservistas movilizables.

En España, la redención y la sustitución eran objeto de controversia en el seno del ejército y causa del creciente antibelicismo y antimilitarismo de la sociedad, particularmente agudo entre sus capas más desfavorecidas ${ }^{63}$. Debido a ello, desde 1887 se hicieron varios intentos para erradicar tan injustos privilegios, sin que ninguno de ellos prosperara, y hubo que esperar a que las trágicas secuelas de la Guerra de Melilla y de la Semana Trágica barcelonesa de 1909 hicieran que políticos y militares se decidieran a eliminarlos.

Seguramente, el presidente Maura no fue consciente del huracán que iba a desencadenarse al llamar a filas a los soldados en situación de Reserva Activa para

62. Vid. Fanjul, Joaquín: Misión social del Ejército. Madrid: Imp. de Eduardo Arias, 1907, pp. XII, 21 y 56, y BETA: Op. cit., 1917, p. 63.

63. Puell De la Villa, Fernando: "Causas del antimilitarismo y anti-belicismo de la ciudadanía española: la incidencia del Servicio Militar (1808-2001)", Revista UNISCI, 51, 2019, pp. 57-61. 
marchar a Melilla. La mayoría de ellos se plegó con resignación a lo inevitable, pero existen suficientes indicios de que el rechazo fue de gran entidad. Nada más conocerse el decreto de movilización comenzó la desbandada de los que pretendían eludirla. Los gobernadores civiles recibieron orden de vigilar puertos marítimos y pasos fronterizos para evitar evasiones y se decretó la suspensión de las ayudas previstas para los emigrantes. Al hacer balance el ministro de la Guerra ante el Congreso de los Diputados, declaró que más de cuatro mil reservistas no acudieron al llamamiento, casi el 18 por ciento de los convocados ${ }^{64}$.

Lo sucedido en Melilla le costó el puesto a Maura y Canalejas se hizo cargo del gobierno, encomendando la cartera de Guerra al general Luque, tándem que dio un impulso definitivo a la reforma del sistema de reclutamiento. El Proyecto presentado al Senado establecía un servicio militar de tres años en activo y quince en la reserva y, sobre todo, derogaba la redención y la sustitución, aunque, con la excusa de compensar la pérdida de los ingresos procedentes de la redención, creaba «un impuesto, pagadero por años completos, que deben satisfacer aquellos mozos que, por causa legal, dejen de prestar una parte del servicio militar, o disfruten prórroga de incorporación a filas o algunas otras ventajas». Dicho impuesto se materializaba en una "cuota" anual, pagadera por los jóvenes que no ingresaran efectivamente en filas -exceptuados por circunstancias familiares o solicitantes de prórrogas (otra de las novedades del proyecto)-, cuya cuantía iba en proporción directa a la renta anual del sujeto afectado, desde una tasa máxima de 2.000 pesetas, asignada a las rentas superiores a las 10.000, hasta las 5 exigidas a sirvientes y jornaleros. Se establecía también otra cuota, llamada "de permanencia», cifrada en 500 pesetas para que quienes desearan prestar solo diez meses de servicio activo y de 1.000 para el caso de optar por cinco meses ${ }^{65}$.

Pese a la oposición de muchos senadores, poco conscientes del clima de indignación que la cuestión suscitaba, el proyecto fue aprobado y pasó al Congreso con la única enmienda de duplicar las cuotas de permanencia. La Comisión que lo dictaminó eliminó la cuota anual, al considerarla un «impuesto global injusto» e incrementó las de permanencia a 1.500 pesetas para servir diez meses y 3.000 para cinco. El texto, remitido a la Comisión Mixta Congreso-Senado y consensuado por liberales y conservadores, se aprobó definitivamente el 29 de junio de 1911 en forma de Ley de Bases. Autorizado Luque por una de sus Disposiciones Finales a redactar la Ley de Reclutamiento y Reemplazo, su articulado definitivo vio la luz el 19 de enero de $1912^{66}$.

Otra notable novedad de esta Ley fue la creación de la Escala de Reserva Gratuita, a fin de disponer de cuadros de mando movilizables en caso de guerra a

64. Puell de la Villa: Op. cit., 2019, pp. 22-23.

65. Real Decreto de 6 de octubre de 1910: GM, 7 de octubre de 1910.

66. Ley de Bases para el Reclutamiento y Reemplazo del Ejército y Real Decreto de 19 de enero de 1912, disponiendo la publicación de los artículos que forman la Ley de Reclutamiento y Reemplazo del Ejército: GM, 30 de junio de 1911 y 21 de enero de 1912, respectivamente. 
coste reducido en tiempo de paz. Dado el ínfimo nivel cultural de la tropa, se optó por nutrirla únicamente con soldados de cuota, que, aparte de pagar esta, habían sufrido un examen para acreditar poseer una formación cultural y militar básica. Y como estos podían fraccionar la prestación de su servicio activo en tres periodos, se previó que en el primero ascendiesen a cabos, a sargentos en el segundo y a alféreces en el tercero, quienes superaran nuevas pruebas de aptitud y realizaran algunos ejercicios tácticos. Los universitarios que hubiesen completado la mitad de su carrera y obtenido previamente los empleos de cabo y de sargento podían ascender a alférez sin necesidad de examinarse.

En 1918, La Cierva transformó la Escala de Reserva Gratuita en Escala de Complemento, que todavía hoy perdura. Los nuevos requisitos exigidos para el ingreso en ella de los soldados de cuota, de los que el más relevante era un mayor tiempo de servicio activo, hizo que la mayoría lo desestimara y que su plantilla nunca llegara a completarse: en 1918 se había previsto que hubiera 30.000 alféreces de complemento, pero en 1931 solo se contaba con $2.117^{67}$.

Es evidente que la Ley de Reclutamiento de 1912 nació a remolque de los acontecimientos de Barcelona y de Melilla. Desde la perspectiva actual, puede cuestionarse la ecuanimidad de la aparición del soldado de cuota, pero entonces significó un verdadero revulsivo social que colmó las aspiraciones de los que venían clamando por la desaparición de las injusticias. También mitigó las reivindicaciones populares, al desaparecer parcialmente el agravio comparativo. Y por otra parte, su presencia en los cuarteles estimuló mejoras en la vida cotidiana de la tropa, impulsó la construcción y acondicionamiento de las instalaciones y, evidentemente, aceleró la recluta de voluntarios en el Protectorado de Marruecos.

\subsection{La vida cotidiana}

La implantación del servicio militar obligatorio hizo que casi todos los muchachos al cumplir veinte años marchasen desde su pueblo a la Caja de Reclutas de la capital de su provincia para ingresar en el ejército ${ }^{68}$. De allí pasaban a un cuartel y se convertían en «reclutas», término aplicado al soldado durante su período de instrucción. Durante este, dedicaban dos horas y media por la mañana y tres por la tarde a hacer instrucción de orden cerrado: saludos, marchas, giros y evoluciones, primero sin armas y luego con ellas. Y durante otra hora, escuchaban una charla sobre la organización del ejército o la teoría del tiro, complementada a veces con una conferencia sobre agricultura, moral o religión. En junio, después de pasar diez semanas en el patio del cuartel aprendiendo a marchar con un fusil y dedicar una mañana a disparar cinco cartuchos, juraban bandera en el mismo

67. Quesada González, José Miguel: "Origen de la Escala de Complemento", Revista de Historia Militar, extraordinario, 2010, pp. 13-52.

68. García Moreno, José F.: Servicio militar en España (1913-1935). Madrid: EMe, 1988, p. 17. 
lugar y accedían al título de "Soldado». En otoño hacían instrucción de compañía y batallón, o algún ejercicio de tiro en el cuartel. Esporádicamente, las compañías realizaban una marcha hacia cualquier descampado de las afueras para realizar un simulacro bélico y, en muy contadas ocasiones, participaban en maniobras a pequeña escala. En resumen, su vida militar propiamente dicha se limitaba a un máximo de ocho meses de instrucción, más o menos intensiva ${ }^{69}$.

En realidad, poco más podía hacerse cuando solo existían en España tres campos de tiro de propiedad estatal -Carabanchel en Madrid, Paterna en Valencia y San Gregorio en Zaragoza- y otros dos arrendados en Burgos y Valladolid con limitaciones de uso en función de las labores agrícolas. De ellos, solo San Gregorio tenía capacidad para que desplegara una brigada y profundidad suficiente para el tiro de artillería. A título orientativo, mientras la superficie total de los cinco campos españoles no llegaba a las 4.000 hectáreas, Alemania dedicaba más de 150.000 a esta misma función y los militares franceses consideraban que las 50.000 existentes no garantizaban el nivel mínimo de instrucción, por lo que auguraban los mayores riesgos para la supervivencia nacional ${ }^{70}$.

Finalizado el periodo de instrucción, los servicios pasaban a ocupar toda la vida del soldado. Además de la "guardia de prevención" para dar seguridad al cuartel y la de "plaza", reliquia de un pasado en el que la seguridad del reino dependía del cordón fronterizo de fortificaciones, debían atender a la conservación y mantenimiento de los cuarteles. Diariamente, cada compañía designaba cuatro "aguadores" para limpiar y abastecer las cubas de la cocina y los dormitorios, dos soldados de "compra" marchaban al mercado y otros dos de "provisiones" distribuían el pan y el combustible de cocinas y lámparas. Cuando un capitán se hacía cargo de la cocina del batallón, nombraba un cierto número de «rancheros» fijos para cocinar y atender los fuegos, ayudados por los que considerase precisos cada día. Aparte, en el dormitorio, un "cuartelero» se encargaba de mantener el orden, impedir sustracciones de prendas y equipos y conservar limpio el local durante el día y, por la noche, el llamado servicio de «imaginarias» velaba el sueño de sus compañeros, atendía a los enfermos y mantenía ardiendo las lámparas de aceite o encendía y apagaba la luz cuando se fue instalando la electricidad ${ }^{71}$.

Muchos oficiales opinaban que era preciso rentabilizar de alguna forma el tiempo que pasaban los soldados en el cuartel, pues, debido a su contacto cotidiano con ellos, conocían de primera mano su lamentable situación cultural, así como su empatía con la conflictividad social. Y para contribuir a solventar ambos problemas, se propusieron regenerar al pueblo durante su servicio militar y que la tropa se licenciara más instruida. A estos efectos, se desarrolló una importante

69. IbáÑez Marín, José: La educación militar. Madrid: Imp. de Felipe Marqués, 1899, pp. 66-69.

70. Dolla, Ángel: "Los campos de instrucción y de tiro", Memorial de Infantería, 1912, I, 6, pp. 670-679.

71. Puell de la Villa, Fernando: «Ritos y rituales cuarteleros». En: Los quintos, Urueña: Fundación Joaquín Díaz, pp. 83-103. 
labor educativa en los cuarteles con el principal objetivo de erradicar el analfabetismo y también el de contrarrestar la influencia de las organizaciones obreras sobre el soldado ${ }^{72}$.

\section{DOCTRINA Y EQUIPAMIENTO}

A comienzos del siglo xx, la aparición de fusiles de repetición, ametralladoras y cañones de tiro rápido, que incrementaban de forma significativa la precisión y eficacia de los fuegos de infantería y artillería, obligó a una profunda revisión de los procedimientos tácticos, al constatar los ejércitos que los ataques frontales contra un enemigo que dispusiera de este tipo de armamento y se protegiera en el terreno mediante fortificaciones ligeras de campaña era una operación cuyo éxito era cada vez más problemático y en la que podían sufrir un desorbitado número de bajas.

\subsection{Los reglamentos tácticos}

Se dice que la infantería es la reina de las batallas y, desde los más remotos tiempos, su actuación se caracterizó por el «movimiento» y por el "choque», vectores a los que, tras la aparición del arcabuz en el siglo xvi, se sumó un tercero, el "fuego", que se vio extraordinariamente potenciado por los avances científicos y tecnológicos que revolucionaron la industria armamentística durante el siglo XIX. La creciente potencia de fuego obligó, además, a dispersar y soterrar a las tropas, así como a uniformarlas menos llamativamente. A consecuencia de todo ello, se abrió un debate sobre el orden de prioridades que debía darse a cada uno de los citados vectores a la hora de reglamentar los procedimientos tácticos y la instrucción de las tropas.

Los militares españoles se enfrentaron por primera vez a las nuevas condiciones de combate impuestas por la revolución armamentística en el teatro de operaciones vasco-navarro a finales de 1873, donde las fuerzas gubernamentales comprobaron la dificultad de atacar con éxito a las tropas carlistas, que habían inventado un nuevo tipo de fortificación de campaña -la llamada «trinchera carlista ${ }^{73}$ - para protegerse de los fuegos de la superior artillería enemiga. Esta experiencia inspiró la redacción del Reglamento Táctico de 1881, que zanjó los

72. Puell de la Villa, Fernando: "Educación de adultos en el servicio militar español», Historia de la Educación, 20, 2001, pp. 311-312.

73. El diseño de las trincheras carlistas revolucionó la fortificación de campaña y fue copiado y perfeccionado durante la Primera Guerra Mundial. «Eran unas trincheras sin parapeto [...] quedando un hombre enteramente oculto. En los taludes de la excavación, había alternadamente pequeños socavones para poner los pies [...]. Para hacer fuego, el tirador trepaba por ellos, descubriendo solo la cabeza»: TORner DE la FuENTE, Eusebio: Fortificación en campaña. Noticia sobre algunos progresos que se han propuesto recientemente. Madrid: Imp. del Memorial de Ingenieros 1888, p. 98. 
agrios debates mantenidos en los años previos y se decantó a favor del "fuego" y en perjuicio del "choque» ${ }^{74}$. Esta doctrina se aplicó para formar a los mandos y adiestrar a la tropa de las unidades a pie que combatieron en Cuba y Filipinas. El énfasis puesto en el vector "fuego" redujo, en opinión de algunos observadores, el espíritu ofensivo, lo que, a su juicio, impedía explotar cualquier éxito táctico sobre los insurgentes y, por ende, hacerse con la victoria ${ }^{75}$.

El final de las guerras ultramarinas coincidió con la entrada en vigor del Reglamento de 1898, fruto de la revisión de los procedimientos operativos tras la adopción del fusil de repetición Mauser modelo 1893, adquirido precipitadamente para dichas guerras y que sería el arma individual básica en las campañas marroquíes ${ }^{76}$. El Reglamento de 1898 mantenía los principios esenciales del de 1881 sobre la primacía del «fuego» en el combate de la infantería y fue también objeto de críticas por supuestamente menoscabar la acometividad de las tropas ${ }^{77}$.

La postura de quienes postulaban por una doctrina más ofensiva, es decir, los partidarios de volver a dar primacía al "movimiento" y al "choque», terminó imponiéndose a comienzos del siglo xx. El cambio de orientación no fue fruto, por extraño que parezca, de ninguna experiencia propia, sino de la de un lejano conflicto: la Guerra Ruso-Japonesa. La lección que se extrajo de ella fue que el bando que mostrase una actitud más ofensiva lograba decidir la batalla a su favor y el "fuego» solo se valoró por el apoyo moral que proporcionaba al atacante, animándolo a avanzar y a buscar el "choque», y por la desmoralización que producía en el defensor, mermando la eficacia de su propio "fuego». Este cambio de óptica se vio reflejado en un tercer Reglamento, aprobado provisionalmente en 1908, cuyo articulado prescribía que el avance se realizara combinando "fuego" $\mathrm{y}$ "movimiento» 78 .

Al haber entrado en vigor solo un año antes de la campaña de Melilla, las unidades implicadas sin duda no estaban familiarizadas con la nueva doctrina, lo que explicaría en parte sus reveses. Estos también se atribuyeron a no haber sabido adaptarse a los métodos de guerra irregular de los cabileños, quienes, pese a estar armados con anticuados fusiles, fueron capaces de infligir bajas significativas cuando las unidades españolas atacaban sin la adecuada preparación artillera.

En cualquier caso, y a pesar de las deficiencias observadas, el Ministerio de la Guerra no consideró necesario alterar los procedimientos tácticos. Al Reglamento

74. Reglamento Táctico de Infantería. Madrid: Depósito de la Guerra, 1881.

75. Sobre la incidencia del nuevo armamento en la conducción de las operaciones, vid. HerRERO: Op. cit., 2017, cap. 3 .

76. El fusil Mauser era un arma de primera clase, y otro tanto puede decirse del posterior mosquetón modelo 1916, una versión acortada del anterior, más ligera y manejable. Sobre sus características, vid. Boado y Castro, José: El fusil Mauser español modelo 1893. Zaragoza: Lit. de E. Portabella, 1895.

77. Reglamento para la Instrucción Táctica de las Tropas de Infantería. Madrid: Depósito de la Guerra, 1898.

78. Reglamento provisional para la Instrucción Táctica de las Tropas de Infantería. Madrid: Depósito de la Guerra, 1908. 
provisional de 1908 siguió el de 1914, que hizo todavía más hincapié en el binomio «fuego-movimiento sin reparar en bajas con tal de asegurar la victoria ${ }^{79}$. Este Reglamento permanecería oficialmente en vigor durante el resto de las campañas marroquíes, pero la experiencia propia y la observada en los beligerantes de la Gran Guerra llevaría a buscar y emplear métodos que se adaptasen mejor a las realidades del combate ${ }^{80}$.

Tras la guerra mundial, se emprendió el proceso para adaptar la doctrina a las lecciones aprendidas, tomando como referencia los cambios introducidos en el ejército francés por razones de proximidad geográfica y cultural. La nueva doctrina francesa abogaba por operaciones meticulosamente planificadas por fases, estrechamente controladas por el mando, con abundancia de medios humanos y bien apoyadas por el fuego de la artillería ${ }^{81}$. Esta fue la doctrina que aplicó el mariscal Petain en Marruecos, a la que añadió de su propia cosecha la táctica de "mancha de aceite» a la que antes se hizo referencia.

El ejército español tardó varios años en adoptar esta doctrina y aplicar sus principios a las operaciones que condujeron a la definitiva pacificación del territorio $^{82}$. Las unidades comenzaron a atacar por varios ejes convergentes sobre el mismo objetivo, organizadas en potentes agrupaciones tácticas con nutrido apoyo artillero y respaldadas por una logística mejorada que les permitía sostener la ofensiva hasta alcanzar su objetivo ${ }^{83}$.

\subsection{El apoyo por el fuego}

La guerra de Marruecos está íntimamente vinculada a la definitiva adopción de la ametralladora por el ejército español ${ }^{84}$. Este había mostrado interés por aquellas "máquinas» -nombre dado a la ametralladora en la jerga castrense- desde finales de la década de 1860, probando diversos modelos belgas, estadounidenses y suecos, que se desecharon por su poca fiabilidad. En 1896, se adquirió apresuradamente una docena de las británicas Maxim con destino a Cuba, que dieron escaso

79. Reglamento Táctico de Infantería. Madrid: Imp. del Colegio de María Cristina para Huérfanos de la Infantería, 1914.

80. Cassinello Pérez, Andrés: «El ejército español en Marruecos. Organización, mandos, tropas y técnica militar». En: Aragón Reyes, Manuel (dir.): El Protectorado español en Marruecos: la historia trascendida. Bilbao: Iberdrola, 2013, v. III, pp. 291-293.

81. PaOli, François-André: La reconversion de l'armée française en 1919. Paris: Ministère des Armées, 1969. 1925.

82. Reglamento para el Empleo Táctico de las Grandes Unidades. Madrid: Depósito de la Guerra,

83. Guerrero Martín, Alberto: "Los procedimientos tácticos en las campañas de Marruecos", Guerra Colonial, 3, 2018, pp. 53-59.

84. Sobre la adopción de la ametralladora por el ejército español, vid. Herrero: Op. cit., 2017, cap. 4, y sobre los diversos modelos utilizados, vid. MorTera Pérez, Artemio: Ametralladoras en España (1867/1936). Valladolid: AF 2010. 
rendimiento por sus frecuentes encasquillamientos; tampoco la actuación de las Gatling estadounidenses empleadas en la batalla de las Lomas de San Juan causaron buena impresión.

No obstante, la ametralladora había llegado para quedarse y, como los demás ejércitos, el español siguió experimentando con otros modelos durante los primeros años del siglo xx, pero sin acabar de decidirse por uno determinado. Dicha indecisión tuvo bastante que ver con que el Arma de Artillería sentía poco entusiasmo hacia la ametralladora y se escudó en la búsqueda de la excelencia mecánica para prolongar las pruebas. Tal vez el punto de inflexión lo marcó la habilidad del representante de la empresa francesa Hotchkiss, quien logró que el Ministerio de la Guerra comprase una veintena en 1907, que después serían fabricadas en España bajo licencia. Con unas y otras, en 1909 se constituyeron 12 Secciones de Ametralladoras adscritas al Arma de Infantería, unas equipadas con las Maxim traídas de Cuba y otras con las nuevas Hotchkiss.

Algunas de ellas recibieron su bautismo de fuego en la campaña de Melilla. La práctica mostró los efectos positivos, tanto de carácter material como moral, de apoyar los ataques con su fuego, aunque la doctrina oficial todavía no contemplase cómo debían utilizarse. Aunque se evidenció que el soldado avanzaba con más ánimo escuchando su tableteo, el Reglamento de 1914 precisó en que su empleo debía ser muy limitado, al objeto de ahorrar munición.

Sorprende que, habiendo tanta preocupación por la acometividad de las tropas, se limitase el empleo de unas armas que tanto la favorecían. Sin embargo, el general Berenguer se mostró decididamente partidario de utilizarlas en Marruecos, al considerarlas idóneas para cubrir frentes discontinuos con menos efectivos y efectuar despliegues menos densos. Además, su alcance, muy superior al del fusil, contribuiría a demostrar la superioridad tecnológica del ejército español y a erosionar la moral del adversario. Berenguer también argumentaba que el mando de estas unidades debía recaer en los jefes de las columnas ${ }^{85}$. Es posible que sus ideas contribuyeran a que, en 1919, se constituyesen compañías de ametralladoras, dotadas con cuatro "máquinas", en cada batallón de infantería desplegado en Marruecos y un escuadrón con seis de ellas en los regimientos de caballería ${ }^{86}$.

La actuación de la artillería también reflejó las transformaciones en la forma de combatir derivadas del incremento de la potencia de fuego. En los primeros ciclos de operaciones en el Kert y en la Yebala, la artillería veía mermada su eficacia al operar desperdigada en baterías e incluso en secciones afectas a las columnas. Por otra parte, a causa del énfasis puesto en la acometividad de las tropas, no daba tiempo a cambiar las piezas de emplazamiento al ritmo exigido.

La rebelión de Abd el-Krim puso de manifiesto la insuficiencia de los métodos empleados hasta entonces, ya que había que enfrentarse por primera vez a un

85. Berenguer: Op. cit., 1918, pp. 100-102 y 107-108.

86. Historia de las campañas de Marruecos. Madrid: Servicio Histórico Militar, 1947-1981, v. II, p. 55 , nota 28 . 
enemigo que disponía de artillería y que empleaba fortificaciones de campaña. A consecuencia de ello, las unidades de artillería se vieron obligadas a realizar fuego de contrabatería y a destruir obras defensivas. A ese objeto se creó la llamada "masa artillera", procedimiento consistente en agrupar bajo un solo mando varias baterías de distintos calibres con la misión de apoyar la acción de conjunto, en lugar de asignar dos o cuatro piezas a cada columna implicada en una operación ${ }^{87}$.

\subsection{El empleo de vehículos blindados}

La guerra de Marruecos también estuvo estrechamente vinculada a la aparición de los vehículos blindados. Desde los primeros momentos, el mando había reconocido su utilidad. El EMC, tras la campaña de 1909, recomendó que se dotase a las fuerzas allí destacadas de automóviles con un blindaje ligero y armados con una ametralladora para poder desplazarse por zonas expuestas al fuego enemigo. $\mathrm{Al}$ año siguiente se fabricó el primero de los llamados «camiones protegidos», cuya fabricación no requería complejas instalaciones. El blindaje de la mayoría de ellos eran meras chapas de hierro, pero proporcionaba una protección razonable contra el fuego de fusil. Su principal defecto era carecer de movilidad en campo abierto y estar obligados a transitar únicamente por caminos en buen estado, lo que limitaba bastante su empleo.

Mucho más prometedor parecía el carro de combate, aparecido en los campos de batalla de la Gran Guerra en 1917. En septiembre de 1921, España compró a Francia seis "carros de asalto" Schneider CA 1 y once Renault FT, que se entregaron a la Escuela Central de Tiro. Como solía ser habitual, inmediatamente surgieron disputas sobre quién debía hacerse cargo de su control y manejo, en este caso entre las Armas de Infantería y Artillería; en cambio, la oficialidad de Caballería no quiso saber inicialmente nada de aquellos «engendros mecánicos». El debate se zanjó con una solución salomónica basada en su armamento: los Schneider, dotados de un cañón de 75 mm, quedarían a cargo de Artillería y los Renault, provistos de una ametralladora, de Infantería. Una vez resuelto esto, partieron rumbo a Marruecos a primeros de marzo de $1922^{88}$.

Su bautismo de fuego tuvo lugar el 15 del mismo mes, a los tres días de su llegada a Melilla, protagonizado por los seis Schneider de la Batería de Carros de Asalto, en apoyo de la unidad de infantería que atacó la posición de Sbuch Sba. La operación se desarrolló con éxito, pero solo dos de ellos continuaban operativos al final, resultando averiados los demás. Poco después, el día 19, le llegó el turno a los Renault de infantería que, junto a unos cuantos camiones protegidos, apoyaron

87. Herrero: Op. cit., 2017, pp. 210-211 y 213.

88. Guerrero Martín, Alberto: «El desarrollo del carro de combate en el ejército español hasta la Guerra Civil (motorización y mecanización del ejército)». En: Gajate Bajo, María y González Piote, Laura (eds.): Guerra y tecnología: interacción desde la Antigüedad al Presente. Madrid: Fundación Ramón Areces, 2017, pp. 453-477. 
a las tropas legionarias que atacaban el poblado de Ambar. La acción se desarrolló con éxito hasta que Ambar fue ocupado, pero los Renault profundizaron demasiado y los rifeños, mucho menos intimidados por su presencia de lo que se había supuesto, lograron dinamitar dos de ellos.

El combate de Ambar fue un jarro de agua fría para las grandes expectativas puestas en los carros, pero no a prescindir de ellos. Los tratadistas respaldaron su utilidad en tierras marroquíes, a condición de prestar atención a sus limitaciones técnicas y a las impuestas por las características del terreno donde actuaran. Las unidades de carros siguieron combatiendo hasta 1927, pero con más prudencia y sin perder nunca el contacto con la infantería 89.

\section{CONClusiones}

Se considera suficientemente probado que en el desastre de Annual incidieron una serie de factores ajenos a los numerosos errores cometidos en la planificación y desarrollo de la operación dirigida al sometimiento del Rif oriental, en la que se encuadró el precipitado abandono de aquella posición y que condujo a la pérdida de la totalidad del territorio ocupado desde 1913. Entre los referidos factores, cabría destacar los siguientes:

- Indefinición, vaivenes y contradicciones en la política gubernamental con respecto a la forma de someter y gestionar civil y militarmente el Protectorado de Marruecos.

- Obsolescencia orgánica y logística del ejército peninsular.

- Carencia de un ejército colonial propiamente dicho.

- Doctrina táctica que preconizaba la ofensiva a ultranza y anteponía los vectores "choque» y "movimiento" al "fuego" de artillería y de ametralladoras.

- Defectuosa formación profesional de los cuadros de mando, al haberse dado total prioridad al estudio de la conducción de las operaciones en una guerra regular e ignorado los principios de la guerra irregular.

- Desmotivación de la oficialidad destacada en Marruecos tras haberse suprimido los ascensos por méritos de guerra debido a la injerencia de las Juntas de Defensa.

- Ínfima moral de combate y escaso adiestramiento de la tropa procedente del reclutamiento forzoso.

- Inadecuación del armamento utilizado en Marruecos, basado esencialmente en el empleo del fusil y sin ninguna dotación de ametralladoras y de vehículos blindados en la zona de operaciones de Melilla.

89. Guerrero Martín, Alberto: "El carro de combate en las campañas de Marruecos», Global Strategy, 29/05/2019: https://global-strategy.org/el-carro-de-combate-en-las-campanas-de-marruecos/. 
